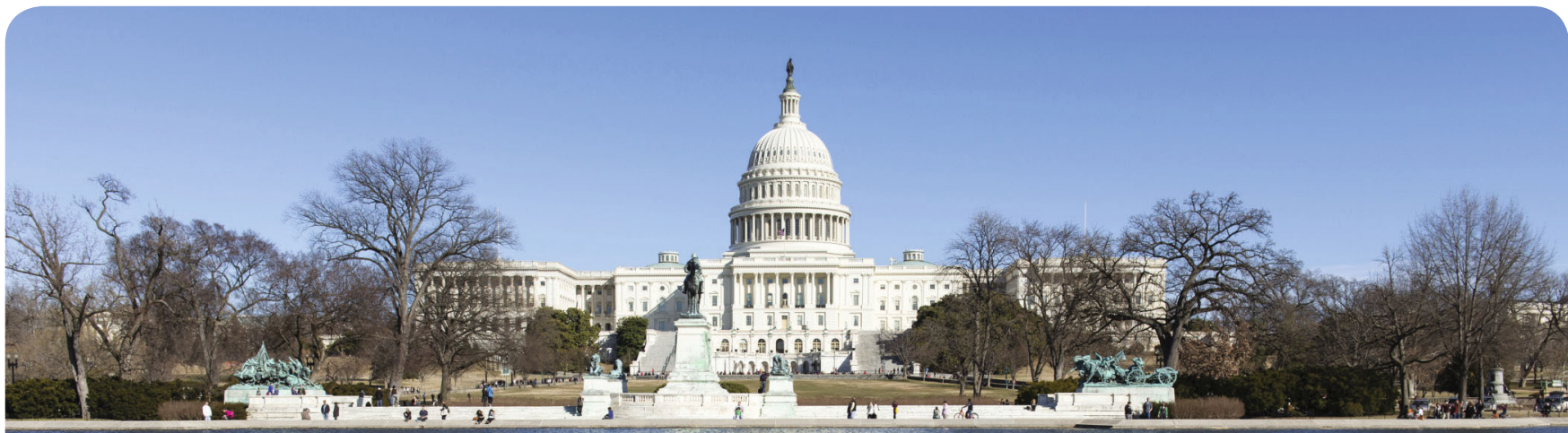

\title{
The Top Ten Lessons Learned from a Year on Capitol Hill
}

Megan Brewster

I spent a year away from the laboratory to see science through a new lensas a fellow on the Senate Committee for Energy and Natural Resources, by virtue of the 2013-2014 TMS/MRS (Materials Research Society) Congressional Science and Engineering Fellowship. As this experience draws to a close, I wanted to share my top ten takeaways from this foray into science policy.

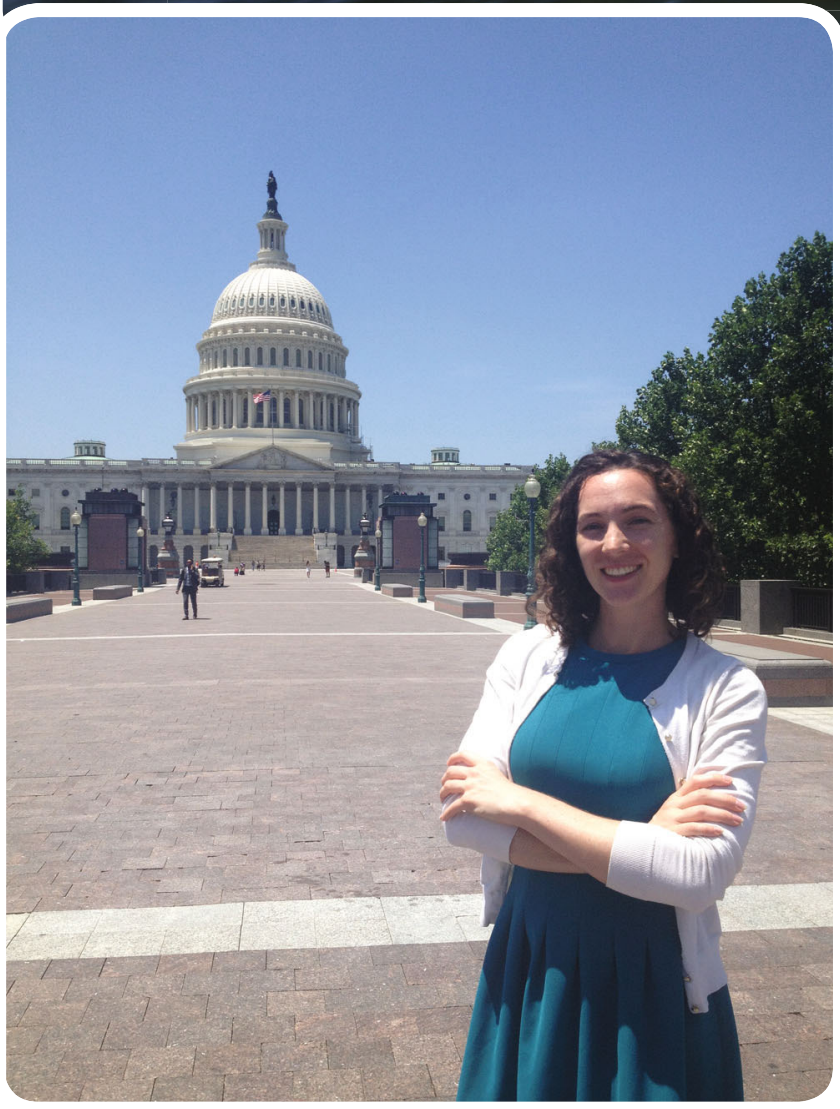

Megan Brewster, 2013-2014 TMS/MRS Congressional Science and Engineering Fellow.

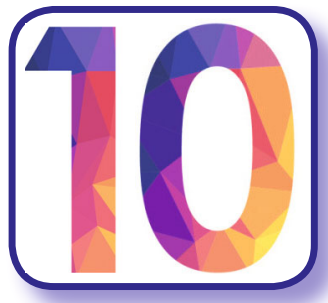

How the U.S. Federal Government Functions (Or Not)

Obviously, a Congressional fellow will learn about Congress. Yet, learning in vivo is infinitely richer. An exceptionally interesting case study is the government dysfunction exemplified by October's shutdown. A news article or perhaps a passage in a textbook may describe previous shutdowns, but it is entirely different to experience it in person. I passed the patchwork of arbitrarily open and closed offices, watched my staff director pick colleagues who would stay home without pay, and thanked the Capitol Police for protecting me even though they were not being compensated.

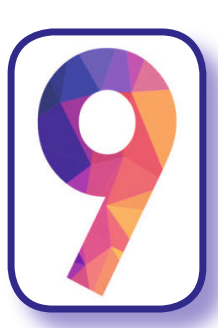

\section{Energy Boot Camp}

After spending seven years researching various energy-related, laboratorylevel minutiae, the opportunity to learn about energy - its origins and forms, the dynamics of domestic and international markets, how it affects our lives - is eyeopening. Two lessons were particularly striking for me. First, while I am a staunch advocate of basic science, I now understand the gravity of a good 
"While I am

a staunch

advocate of

basic science,

I now understand

the gravity of a

good business

case."

\section{"Exposure}

to differing

viewpoints is not

only healthy —It

is the only way

to move the

conversation

forward." business case. No matter how promising the technology, an invention without market-based motivations may never see the light of commercialization. Second, it is supremely difficult to assess a decision's true impact, free of opinion-based aberrations. For example, what is the impact of the approval of the Keystone XL pipeline, or the extension of production tax credits for wind energy, or the World Trade Organization's ruling regarding China's role in the rare earth element market? In the end, answers to such questions are anyone's best guess.

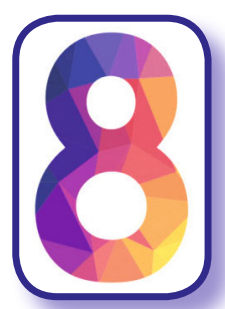

\section{Be Nice to Everyone. Or, Don't Talk Politics in Elevators}

Your subway car companion might be an elected member of Congress. Your hallway escort might be a graduate of West Point. Your office's mailroom worker might work her way up the hierarchy to become the office's director. I provide these examples from my fellowship to illustrate the importance of being nice. To everyone. We live in an exceptionally small world, and while it shrinks further every day, I believe that it shrinks fastest in D.C. One critical consequence is that you never know who might be sharing your elevator, and not just the individuals themselves, but also their network, and their network's network. Not even talk about local sports teams is safe ... best to stick to the weather.

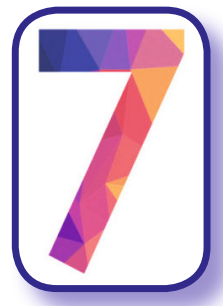

\section{Anyone Can Learn STEM}

Like any sector, civil servants are ready to work wherever work is needed.

They are not afraid to delve into new topics, including science, technology, engineering, and mathematics (STEM) fields. I have always rejected the notion of binary STEM abilities (i.e., being "good at [insert STEM field here]"). Prior to my fellowship, I knew that Capitol Hill was filled with smart (albeit non-STEM) people. But I now fully appreciate their capacity for technical tenacity. They may or may not enjoy math, but they will wade deeply into the numbers if the job calls for it.

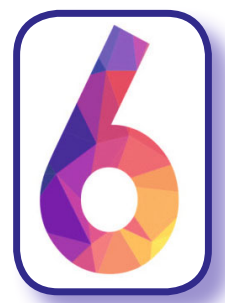

\section{Regulations Shape Markets}

Government plays a critical role in technology development, and not just through financially supporting research. Regulations, which may be shaped by all three branches of the federal government, have profound consequences on markets, and thus, technology (see lesson \#9). For example, the U.S. Environmental Protection Agency's recent Clean Power Plan proposed rule might accelerate the commercialization and deployment of carbon capture and sequestration, renewable energy, and energy storage technologies. Many companies monitor regulatory environments when deciding whether or not to enter markets, and those that previously played wait-and-see may now choose to dive in.

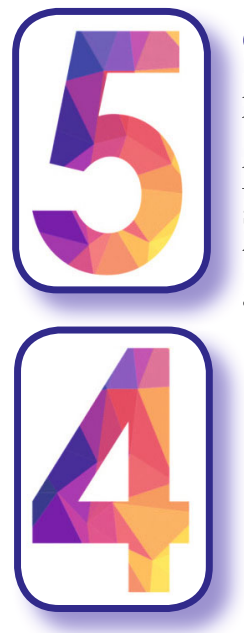

\section{Get to the Point}

A common exercise for a new Congressional fellow is to summarize a broad STEM topic - say nanotechnology or climate change - into one page. Then distill it further - cut it down to one paragraph, and then to one sentence. Make it accurate, make it relevant, and do it fast. You'll be lucky to get the member of Congress to read the first paragraph of your memo, so also have a short (i.e., ten seconds long) elevator speech in your quiver.

\section{Choose Your Own Adventure}

On Capitol Hill, it seems that all possible outcomes are equally probable. For example, I weathered a leadership transition on the Senate Committee for Energy and Natural Resources, but I could have also left with the outgoing team or switched offices entirely. Each scenario had unique pros and cons, but never had I ever faced so many opportunities without a clear 
ranking. Anything could happen, and the options were still dynamic when I had to make my choice. In D.C., uncertainty is the norm, and decisions must occasionally be made with imperfect information.

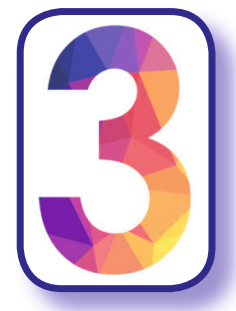

\section{Opinions/Politics Evolve}

Over the course of the fellowship, my knowledge base grew, world situations unfolded, and my network (and exposure to differing viewpoints) opened. My political stance correspondingly shifted as I revaluated hypotheses in light of new data. I found myself stepping back to admire each issue's complexity, and in some cases,

dropping binary opinions altogether to fully appreciate the intricacies. This has multiple consequences. First, the evolution of an opinion is not political flip-flopping - It is the scientific method at work. Second, a nuanced stance is thoughtful and sometimes necessary to fully encompass a complicated issue. Finally, exposure to differing viewpoints is not only healthy, it is the only way to move the conversation forward.

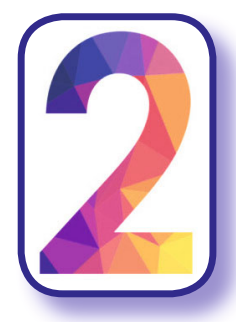

\section{Observing is Learning}

That observing is learning may seem obvious to STEM practitioners, so I want to underscore the absence of the rest of our handy learning toolkit. Here, I'm referring specifically to questions. I was speechless when a colleague, who is a lawyer and whose parents are lawyers, told me that he never asked a question to which he didn't already know the answer. Imagine, learning through observation, but without the ability to question. As an avid questioner, I will continue to learn this lesson for many years. But, one thing I can say for sure-Much can be gleaned from a single piece of evidence with sufficient time to silently mull over it.

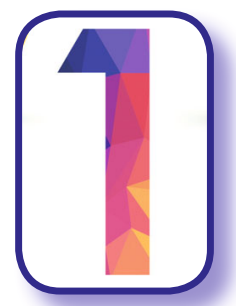

\section{STEM Is Not an Island}

Although STEM enjoys public support, we cannot take this support for granted, especially when considering current fiscal constraints. We do not and cannot practice STEM in a vacuum. Further, STEM is not immune to scandal or bias (e.g., data fabrication and implicit bias against women and minorities, respectively). We must continue to justify our work, track our broader impacts, and measure the returns on investments.

My fellowship on the Senate Committee for Energy and Natural Resources has fundamentally changed my perceptions of STEM. My world view is now broader and more colorful with new caveats. I developed a nuanced intuition of the energy world's individual players and their bigpicture motivations. If, like me, you also want to know beyond just the "how" of any science policy topic - from energy, to health, to agriculture, and beyond - then I strongly encourage you to apply for the TMS/MRS Congressional Science and Engineering Fellowship. It's guaranteed to be a wild ride.

Prior to her appointment as the 2013-2014 TMS/MRS Congressional Science and Engineering Fellow, Megan Brewster was a materials scientist at GE Global Research where she supported the Durathon battery start-up. She received her Ph.D. in materials science and engineering from the Massachusetts Institute of Technology and her B.S. in materials science and engineering from the University of Washington.
What Lessons Can You Learn as the Next Congressional Science and Engineering Fellow?

TMS and the Materials Research Society (MRS) are now accepting applications for the jointly sponsored 2015-2016 Congressional Science and Engineering Fellowship.

To be considered for the fellowship, applicants must have a record of success in research or scholarship in a field relevant to materials science, while also demonstrating a strong interest in applying scientific and technical knowledge to U.S. public policy issues. Potential fellowship candidates should also be able to work quickly and communicate effectively to both scientific and nonscientific audiences on a wide variety of topics, as well as be able to work cooperatively with individuals having diverse viewpoints. An applicant is expected to be a member or an applicant for membership of TMS or MRS, and must have a Ph.D. by September 1, 2014. U.S. citizenship is not required, but applicants must be authorized to work in the United States.

The American Association for the Advancement of Science Congressional Science and Engineering Fellows Program is operated as a cooperative effort of approximately 30 national scientific and engineering societies that provide an opportunity for accomplished scientists and engineers with public policy interests to learn about and contribute to the policy-making processes in the U.S. Congress.

For additional information on the 2015-2016 TMS/MRS Congressional Science and Engineering Fellowship, contact Mary Samsa, TMS Foundation and Public Affairs Manager, at msamsa@tms.org. 